\title{
METODOLOGIA PARA ESTIMAÇÃO DE EXTERNALIDADES AGROPECUÁRIAS DECORRENTES DA CONSTRUÇÃO DE RESERVATÓRIOS
}

\section{METHODOLOGY TO ESTIMATE LIVESTOCK AND AGRICULTURAL EXTERNALITIES DERIVED FROM HYDRO POWER RESERVOIRS CONSTRUCTION}

\begin{abstract}
VINÍCIUS VERNA M. FERREIRA
Engenheiro Eletricista - UFMG. Mestre em Ciências e Técnicas Nucleares - UFMG. Doutor em Saneamento, Meio Ambiente e Recursos Hídricos - UFMG. Tecnologista Pleno do CDTN/CNEN

\section{CARLOS BARREIRA MARTINEZ}

Engenheiro Civil - EFEI. Mestre em Engenharia Mecânica - EFEI. Doutor em Planejamento de Sistemas Energéticos UNICAMP. Professor do Departamento de Engenharia Hidráulica e Recursos Hídricos da Escola de Engenharia da UFMG

\section{BRUNO RABELO VERSIANI}

Engenheiro Civil - UFMG. Mestre em Mecanique Des Milieux Geophysiques Et Environnemen - Universite de Grenoble/ França. Doutor em Mecanique Des Milieux Géophysiques et Environnemen - Universite de Grenoble/França. Professor do Departamento de Engenharia Hidráulica e Recursos Hídricos da Escola de Engenharia da UFMG
\end{abstract}

\section{Recebido: 23/08/05 Aceito: 09/10/07}

\section{RESUMO}

O objetivo deste trabalho é o de apresentar uma metodologia que avalia e quantifica as perdas agropecuárias que ocorrem quando da construção de reservatórios para a geração de energia elétrica. Foram estudados sete reservatórios da CEMIG situados no Estado de Minas Gerais. A produção agropecuária foi obtida de acordo com dados do IBGE relativos a 2001. As áreas municipais alagadas foram calculadas com base em dados georeferenciados fornecidos pela ANEEL. Ao final, os valores das externalidades foram comparados ao custo da energia elétrica e ao PIB municipal para a avaliação da significância dos resultados. Verificou-se que quanto maior o valor da área municipal alagada, mais relevante será a externalidade. Como exemplo, o município de Grupiara tem 40\% de suas terras inundadas pelo lago de Emborcação. Entre todas as localidades estudadas, esta foi aquela onde a externalidade agropecuária foi mais relevante.

PALAVRAS-CHAVE: Reservatórios, externalidades, agropecuária, hidrelétricas.

\begin{abstract}
The objective of this work is to present a methodology that evaluates and quantifies the agricultural and livestock losses that happen when reservoirs for the electric power generation are constructed. Seven CEMIG reservoirs, located in Minas Gerais State were studied The agricultural and livestock production were obtained in agreement on with IBGE 2001 data. The municipal areas were calculated based in georeference data supplied by ANEEL. The externalities values were compared to the electric power cost and to municipal gross domestic product to evaluate the significance of the results. It was verified that as larger is the value of the municipal flooded area, more relevant is the externality. As example, the city of Grupiara has $40 \%$ of their lands flooded by the lake of Emborcação. Among all the cities studied, that was the one where the agricultural and livestock externalities were more significant.
\end{abstract}

KEYWORDS: Dams, externalities, agricultural and livestock, hydro power plants.

\section{INTRODUÇÃO}

O entusiasmo em relação à implementação das grandes barragens para geração de energia hidrelétrica cresceu consideravelmente nas últimas décadas. Alguns países têm um grande desejo de construir projetos de prestígio, sustentados pela visão ideológica do progresso humano através do controle da natureza. Grandes barragens têm sido tradicionalmente vistas como soluçōes econômicas e ambientais para os problemas energéticos. Tal crença fez com que em 2001 houvesse mais de 40 mil barragens em todo o mundo, de acordo com o último relatório do Comitê Mundial de Barragens (World Commission on Dams, 2001), sendo que mais de $85 \%$ destas foram construídas nos últimos quarenta anos. Somente a China construiu em média cerca de
600 grandes barragens, anualmente, nos 30 anos subsequentes a revolução comunista (McCully, 1996).

Entretanto, o entusiasmo que tomava conta do setor, decresceu nos últimos tempos por várias razões. Os projetos hidrelétricos têm sido duramente criticados, pois quando analisados de forma imparcial se torna claro que os benefícios das grandes represas têm sido geralmente muito exagerados, enquanto 
que os custos esperados - econômicos, sociais e ambientais, têm sido muitas vezes subestimados ou completamente ignorados.

As conseqüências ambientais das grandes barragens têm sido devastadoras. A construção de reservatórios representa não somente uma imensa perda de terras, mas também de terrenos férteis e de inúmeros ecossistemas. Por exemplo, o reservatório de Três Gargantas na China afeta de modo considerável uma área responsável por cerca de $40 \%$ da produção agrária do país (Morrish, 1997).

Além dos danos ao meio ambiente, as conseqüências à população, quando da construção de grandes reservatórios, têm sido desastrosas. O número de pessoas que teve suas terras inundadas por barragens é certamente imenso; 40 milhōes é geralmente admitido como uma estimativa conservadora, embora especialistas sugiram um número mais realista, uma estimativa da ordem de 80 milhóes de pessoas, sendo que a China e a Índia conjuntamente são responsáveis por $75 \%$ deste total (World Commission on Dams, 2001).

Outra questão problemática diz respeito ao ressarcimento financeiro. Através do mundo, as pessoas que tiveram suas terras alagadas receberam uma compensação irrisória - isso quando receberam algo. Um estudo do Banco Mundial atesta que mais da metade dos projetos de barragens não envolve nenhum tipo de plano de reassentamento ou algo equivalente, e que o número de pessoas afetadas é sempre subestimado (Murphy, 2001).

Contudo, aqueles que são reassentados em geral não conseguem manter o mesmo nível de vida que possuíam anteriormente. Como exemplo, a renda média dos seis mil fazendeiros que foram reassentados quando da construção da hidrelétrica de Kiambere, no Quênia, caiu em média 82\%. Não apenas esses criadores perderam grande parte do seu gado durante o processo de reassentamento, mas receberam terras menos férteis e de menor valor (Caufield, 1996). Os especialistas estão de acordo que reassentamentos forçados criam um tremendo stress sociocultural, psicológico e fisiológico (Weist, 1995). A comunidade reassentada para a construção da barragem Kariba, em Zâmbia, vive em meio a uma tremenda guerra civil. Uma pesquisa efetuada na região mostrou que, de acordo com os entrevistados, as maiores dificuldades nos últimos anos surgiram logo após o reassentamento (Scuder, 1993).

Comprovadamente, logo após a proposição da construção de uma barragem, os preços das propriedades na regiāo despencam, os bancos se recusam a efetuar empréstimos e nenhuma nova escola ou posto de saúde é construído. A situação se torna ainda mais complexa pois o tempo de planejamento/construção é muito longo quando comparado com outros empreendimentos. Como exemplo, o reservatório de Três Gargantas, na China, teve seus estudos preliminares iniciados em 1919, sendo que o projeto terminou em 1955; contudo a sua construção somente teve início na década de 1990 (Edmonds, 1992).

Entretanto, aqueles que são reassentados pelos projetos constituem apenas a parte visível das vítimas das grandes barragens. Milhões perderam suas terras e casas para rodovias, linhas de transmissão e pelo desenvolvimento industrial subseqüente. Alguns dos maiores problemas sociais a longo prazo das barragens são sentidos pelas pessoas que vivem a jusante. $\mathrm{Na}$ África, a perda da inundação anual a jusante das barragens comprometeu a pesca, as pastagens $\mathrm{e}$ as tradicionais culturas inundadas. Enquanto que a barragem nigeriana de Kainji diretamente reassentou 44 mil pessoas, centenas de milhares de nigerianos deixaram de ter seus pastos e plantações irrigadas pela inundação anual. Uma pesquisa demonstrou que três quartos dos fazendeiros que sobreviviam com a ajuda da irrigação nas vilas afetadas pela represa Kainji, desistiram completamente de suas atividades agrárias (McCully, 1996).

Além dos impactos visíveis e facilmente identificáveis, existem também outros ocorrem de forma indireta e são difíceis de mensurar, denominados externalidades. Subentende-se como externalidades negativas os impactos trazidos por uma tecnologia de geração, cujos custos não são incorporados ao preço do produto e, consequentemente, não são repassados aos consumidores, sendo arcados por uma terceira parte, ou pela sociedade como um todo. A monetarização destas externalidades dá origem aos custos externos ou sócio-ambientais (Jacomino et al, 2000).

As principais externalidades negativas consideradas na geração de energia elétrica, pelas várias fontes e tecnologias empregadas, são os danos ao meio am- biente, às edificações e principalmente à saúde da população sob influência do empreendimento e o aquecimento do planeta devido as emissóes de gases de efeito estufa. A intensidade desses danos depende das características ambientais do local onde a usina está localizada, densidade populacional e condiçôes meteorológicas, entre outros fatores, como as medidas de segurança empregadas e tecnologias utilizadas para a redução das emissões.

Entretanto, são vários os problemas para as estimativas das externalidades originadas pela geração de energia elétrica. Pode-se citar a interdependência entre as tecnologias utilizadas e a localização das usinas geradoras, as incertezas nas causas e natureza dos impactos para a saúde e o ambiente, os reduzidos estudos de avaliação econômica e as questôes metodológicas envolvendo a utilização dos resultados econômicos e ambientais (Ferreira, 2004).

Este trabalho tem como objetivo propor uma metodologia no intuito de avaliar as perdas agropecuárias oriundas do alagamento de terras quando da construção de uma usina hidrelétrica. Os objetivos específicos são comparar o valor da perda agropecuária ao custo de geração da usina associada a este alagamento, e ao Produto Interno Bruto - PIB dos municípios parcialmente inundados, de forma a verificar se esta perda é significativa.

\section{METODOLOGIA}

\section{Modelagem do cenário}

Para o presente trabalho foram considerados sete reservatórios no Estado de Minas Gerais. Estes lagos são representativos de diversas regiōes do Estado e de tipos de usinas.

As Tabelas 1 a 7 apresentam alguns dados obtidos junto ao setor de geoprocessamento da ANEEL - Agência Nacional de Energia Elétrica. Essas informações retratam a situação dos municípios mineiros que tem parte de suas terras alagadas por cada um dos reservatórios em estudo, e serão utilizadas para se estimar a produção agropecuária na área inundada e o valor da externalidade associado a esta produção perdida. Ressalta-se aqui que uma significativa parcela do lago de Emborcação se encontra no Estado de Goiás; todavia os municípios goianos limítrofes ao lago não estão contemplados no cálculo 
das externalidades agropecuárias. Os outros reservatórios estão integralmente no Estado de Minas Gerais. Todos eles pertencem a CEMIG - Companhia Energética de Minas Gerais.

\section{Fonte de dados agropecuários}

O site do IBGE (IBGE, 2003), Instituto Brasileiro de Geografia e Estatística, possui um vasto banco de dados agropecuários em nível municipal. Tais informações foram utilizadas para a confecção de uma planilha que contém os dados listados abaixo, relativos ao Estado de Minas Gerais, tendo 2001 como ano base. Estas informações são apresentadas sob a forma de tabelas, contendo os seguintes dados:
- Efetivo dos rebanhos (número de cabeças)

- Produtos de origem animal

- Silvicultura

- Lavouras temporárias

- Lavouras permanentes.

- Horticultura

- Produtos de extração vegetal (Reais)

- Valor das cabeças abatidas

\section{Estimação da produção perdida}

Para a avaliação das externalidades agropecuárias, é necessária a obtenção do valor estimado da produção perdida na área alagada, em cada um dos municípios limítrofes aos lagos. Inicialmente isto foi efetuado através de uma regra de três simples, apresentada na Equação 1:

$\mathrm{P} 2=\mathrm{P} 1 * \mathrm{~A} 2 / \mathrm{A} 1$

na qual:

P2=produção estimada na área alagada;

P1=produção municipal (dados do IBGE);

A2=área municipal alagada (dados da ANEEL);

A1=área municipal não alagada (dados da ANEEL).

Desta forma, calculou-se para cada um dos produtos agropecuários anteriormente citados quais seriam as quantidades que deixariam de ser produzidas e o valor em Reais destas produções, para cada um dos municípios em estudo.

Tabela I - Dados do lago de Três Marias

\begin{tabular}{cccccc}
\hline UHE Três Marias & $\begin{array}{c}\text { Área dos } \\
\text { municípios } \\
\mathrm{km}^{2}\end{array}$ & $\begin{array}{c}\text { Área municipal } \\
\text { Alagada } \\
\mathrm{km}^{2}\end{array}$ & $\begin{array}{c}\text { Percentual } \\
\text { do lago }\end{array}$ & $\begin{array}{c}\text { Relação área } \\
\text { alagada/ } \\
\text { não alagada }\end{array}$ & $\begin{array}{c}\text { Área municipal } \\
\text { não alagada } \\
\mathrm{km}^{2}\end{array}$ \\
\hline Abaeté & $1.816,85$ & 74,07 & 6,67 & $4,25 \%$ & $1.742,78$ \\
Biquinhas & 457,22 & 1,22 & 0,11 & $0,26 \%$ & 456,00 \\
Felixlândia & $1.553,35$ & 157,90 & 14,21 & $11,31 \%$ & $1.395,45$ \\
Morada Nova de Minas & $2.084,61$ & 495,97 & 44,66 & $31,22 \%$ & $1.588,63$ \\
Paineiras & 637,75 & 54,64 & 4,92 & $9,37 \%$ & 583,10 \\
Pompeu & $2.557,73$ & 93,38 & 8,40 & $3,79 \%$ & $2.464,34$ \\
São Gonçalo Abaeté & $2.687,41$ & 18,83 & 1,69 & $0,70 \%$ & $2.668,57$ \\
Três Marias & $2.675,15$ & 214,50 & 19,31 & $8,71 \%$ & $2.460,65$ \\
Total & $14.470,09$ & $1.110,54$ & 100,00 & $8,31 \%$ & $13.359,54$ \\
\hline
\end{tabular}

Fonte: ANEEL - 2004

Tabela 2 - Dados do lago de Nova Ponte

\begin{tabular}{cccccc}
\hline UHE Nova Ponte & $\begin{array}{c}\text { Área dos } \\
\text { Municípios } \\
\mathrm{km}^{2}\end{array}$ & $\begin{array}{c}\text { Área municipal } \\
\text { Alagada } \\
\mathrm{km}^{2}\end{array}$ & $\begin{array}{c}\text { Percentual } \\
\text { do lago }\end{array}$ & $\begin{array}{c}\text { Relação área } \\
\text { alagada/ } \\
\text { não alagada }\end{array}$ & $\begin{array}{c}\text { Área municipal } \\
\text { não alagada } \\
\mathrm{km}^{2}\end{array}$ \\
\hline Iraí de Minas & 357,57 & 57,70 & 14,52 & $19,24 \%$ & 299,87 \\
Nova Ponte & $1.105,76$ & 41,53 & 10,45 & $3,90 \%$ & $1.064,23$ \\
Patrocínio & $2.866,55$ & 105,19 & 26,47 & $3,80 \%$ & $2.761,36$ \\
Pedrinópolis & 357,68 & 56,64 & 14,25 & $18,81 \%$ & 301,04 \\
Perdizes & $2.450,14$ & 111,60 & 28,08 & $4,77 \%$ & $2.338,54$ \\
Sacramento & $3.071,45$ & 2,10 & 0,52 & $0,06 \%$ & $3.069,35$ \\
Santa Juliana & 727,35 & 18,65 & 4,69 & $2,63 \%$ & 708,69 \\
Serra do Salitre & $1.297,74$ & 3,97 & 1,00 & $0,30 \%$ & $1.293,77$ \\
Total & $12.234,28$ & 397,40 & 100,000 & $3,35 \%$ & $11.836,88$ \\
\hline
\end{tabular}

Fonte: ANEEL - 2004 
Tabela 3 - Dados do lago de Itutinga

\begin{tabular}{cccccc}
\hline UHE Itutinga & $\begin{array}{c}\text { Área dos } \\
\text { Municípios } \\
\mathrm{km}^{2}\end{array}$ & $\begin{array}{c}\text { Área municipal } \\
\text { alagada } \\
\mathrm{km}^{2}\end{array}$ & $\begin{array}{c}\text { Percentual } \\
\text { do lago }\end{array}$ & $\begin{array}{c}\text { Relação área } \\
\text { alagada/ } \\
\text { não alagada }\end{array}$ & $\begin{array}{c}\text { Área municipal } \\
\text { não alagada } \\
\mathrm{km}^{2}\end{array}$ \\
\hline Itutinga & 372,50 & 0,52 & 25,81 & $0,14 \%$ & 371,98 \\
Nazareno & 323,51 & 1,51 & 74,18 & $0,46 \%$ & 322,00 \\
Total & 696,01 & 2,03 & 100,00 & $0,29 \%$ & 693,98 \\
\hline
\end{tabular}

Fonte: ANEEL - 2004

Tabela 4 - Dados do lago de Salto Grande

\begin{tabular}{cccccc}
\hline UHE Salto Grande & $\begin{array}{c}\text { Área dos } \\
\text { Municípios } \\
\mathrm{Km}^{2}\end{array}$ & $\begin{array}{c}\text { Área municipal } \\
\text { alagada } \\
\mathrm{km}^{2}\end{array}$ & $\begin{array}{c}\text { Percentual } \\
\text { do lago }\end{array}$ & $\begin{array}{c}\text { Relação área } \\
\text { alagada/ } \\
\text { não alagada }\end{array}$ & $\begin{array}{c}\text { Área municipal } \\
\text { não alagada } \\
\mathrm{km}^{2}\end{array}$ \\
\hline Braúnas & 377,15 & 2,77 & 47,59 & $0,74 \%$ & 374,38 \\
Dores de Guanhães & 381,82 & 1,86 & 32,04 & $0,49 \%$ & 379,95 \\
Guanhães & $1.076,03$ & 1,18 & 20,36 & $0,11 \%$ & $1.074,84$ \\
Total & $1.835,01$ & 5,82 & 100,00 & $0,31 \%$ & $1.829,18$ \\
\hline
\end{tabular}

Fonte: ANEEL - 2004

Tabela 5 - Dados do lago de Emborcação

\begin{tabular}{cccccc}
\hline UHE Emborcação & $\begin{array}{c}\text { Área dos } \\
\text { Municípios } \\
\mathrm{km}^{2}\end{array}$ & $\begin{array}{c}\text { Área municipal } \\
\text { alagada } \\
\mathrm{km}^{2}\end{array}$ & $\begin{array}{c}\text { Percentual } \\
\text { do lago }\end{array}$ & $\begin{array}{c}\text { Relação área } \\
\text { alagada/ } \\
\text { não alagada }\end{array}$ & $\begin{array}{c}\text { Área municipal } \\
\text { não alagada } \\
\mathrm{km}^{2}\end{array}$ \\
\hline Abadia dos Dourados & 894,51 & 28,53 & 6,59 & $3,29 \%$ & 865,97 \\
Araguari & $2.730,63$ & 22,17 & 5,12 & $0,81 \%$ & $2.708,45$ \\
Cascalho Rico & 367,73 & 77,28 & 17,87 & $26,61 \%$ & 290,44 \\
Douradoquara & 313,37 & 46,68 & 10,74 & $17,50 \%$ & 266,68 \\
Estrela do Sul & 820,33 & 6,08 & 1,40 & $0,74 \%$ & 814,24 \\
Grupiara & 192,55 & 77,43 & 17,90 & $67,25 \%$ & 115,12 \\
Monte Carmelo & $1.353,67$ & 10,43 & 2,41 & $0,77 \%$ & $1.343,23$ \\
Total & $6.672,81$ & 268,63 & 62,06 & $4,19 \%$ & $6.404,18$ \\
\hline
\end{tabular}

Fonte: ANEEL - 2004

Tabela 6 - Dados do lago de Camargos

\begin{tabular}{cccccc}
\hline UHE Camargos & $\begin{array}{c}\text { Área dos } \\
\text { Municípios } \\
\mathrm{km}^{2}\end{array}$ & $\begin{array}{c}\text { Área municipal } \\
\text { alagada } \\
\mathrm{km}^{2}\end{array}$ & $\begin{array}{c}\text { Percentual } \\
\text { do lago }\end{array}$ & $\begin{array}{c}\text { Relação área } \\
\text { alagada/ } \\
\text { não alagada }\end{array}$ & $\begin{array}{c}\text { Área municipal } \\
\text { não alagada } \\
\mathrm{km}^{2}\end{array}$ \\
\hline Carrancas & 727,82 & 20,31 & 40,26 & $2,87 \%$ & 707,50 \\
Itutinga & 372,50 & 4,77 & 9,45 & $1,29 \%$ & 367,73 \\
Madre Deus de Minas & 493,56 & 9,01 & 17,87 & $1,86 \%$ & 484,55 \\
Nazareno & 323,51 & 3,28 & 6,50 & $1,02 \%$ & 320,22 \\
São João Del Rei & $1.463,59$ & 13,07 & 25,91 & $0,90 \%$ & $1.450,51$ \\
Total & $3.381,00$ & 50,46 & 100,00 & $1,51 \%$ & $3.330,53$ \\
\hline
\end{tabular}

Fonte: ANEEL - 2004 
Tabela 7 - Dados do lago de Miranda

\begin{tabular}{cccccc}
\hline UHE Miranda & $\begin{array}{c}\text { Área dos } \\
\text { municípios } \\
\mathrm{km}^{2}\end{array}$ & $\begin{array}{c}\text { Área municipal } \\
\text { alagada } \\
\mathrm{km}^{2}\end{array}$ & $\begin{array}{c}\text { Percentual } \\
\text { do lago }\end{array}$ & $\begin{array}{c}\text { Relação área } \\
\text { alagada/ } \\
\text { não alagada }\end{array}$ & $\begin{array}{c}\text { Área municipal } \\
\text { não alagada } \\
\mathrm{km}^{2}\end{array}$ \\
\hline Indianópolis & 833,87 & 21,04 & 40,18 & $2,58 \%$ & 812,82 \\
Nova Ponte & $1.105,77$ & 7,27 & 13,90 & $0,66 \%$ & $1.098,49$ \\
Uberaba & $4.512,14$ & 3,14 & 6,00 & $0,07 \%$ & $4.508,99$ \\
Uberlândia & $4.115,82$ & 20,89 & 39,91 & $0,51 \%$ & $4.094,92$ \\
Total & $10.567,60$ & 52,36 & 100,00 & $0,49 \%$ & $10.515,23$ \\
\hline
\end{tabular}

Fonte: ANEEL - 2004

Como exemplo, vamos considerar a usina de Itutinga. O lago da hidrelétrica banha dois municípios, conforme apresentado na Tabela 3: Itutinga e Nazareno. Para estas duas localidades, o quociente entre a área municipal alagada e a área municipal não alagada é de respectivamente, 0,00139 e 0,00469. Como este é um lago relativamente pequeno, apenas uma pequena fração municipal é alagada, o que não ocorre com lagos maiores como Três Marias e Emborcação. O município de Morada de Nova de Minas tem 23\% de suas terras alagadas pelo lago de Três Marias, enquanto que Grupiara tem $40 \%$ de sua superfície tomada pela represa de Emborcação (Tabelas 1 e 5).

Obtidos os quocientes entre as áreas municipais alagadas e não alagadas, estes foram multiplicados, pelas quantidades produzidas e seus respectivos preços em 2001, para cada um dos produtos agropecuários anteriormente citados, existentes no município em questão.

\section{Correção em função da configuração de ocupação do solo da área alagadá}

Segundo estudos realizados na época do projeto da hidrelétrica de Miranda, a área do reservatório inundou os seguintes tipos de vegetação: cerradão, cerrado, campo sujo/pasto sujo, campo de várzea, campo de murundus, pasto limpo, culturas perenes, culturais anuais, reflorestamento e reflorestamento cortado (Rosa et al, 1998). A tabela 8 apresenta os valores percentuais da área alagada pelo lago da UHE Miranda em função do tipo de ocupação do solo.

Desta forma, para toda a produção agropecuária em estudo, aplicou-se um segundo valor de ajuste, visto que boa parte da área alagada não era efetivamente utilizada em atividades agropecuárias. Para trabalhar-se com um valor conservativo, os valores das quantidades produzidas e do valor da produção foram multiplicados por 0,032 no caso de produtos agrícolas, e 0,0668 quando se tratava de produtos de origem pecuária (Tabela 8 ).

Como boa parte dos reservatórios em estudo neste trabalho foi implantada há mais de 20 anos, torna-se bastante difícil encontrar informaçōes similares àquelas apresentadas na Tabela 8 para outros lagos. Quando o objeto do estudo for uma usina recentemente construída, é possível que se tenha um registro dos dados referentes ao uso e ocupação do solo. Isso possibilitará uma correção em função da configuração da área inundada.

$\mathrm{Na}$ ausência de informações similares para outras usinas, a configuração da área alagada de Miranda foi utilizada para todos os lagos em estudo. A falta destes dados compromete os resultados das externalidades obtidos para as demais UHEs, porém não prejudica o objetivo maior que é o desenvolvimento de uma metodologia até então inexistente.

Como exemplo concreto, no ano de 2001, o município de Uberlândia produziu 61,981 milhóes de litros de leite; aplicada a equação 1 para os dados da UHE Miranda, o valor proporcional na área alagada é de 33.413 litros.

Produção estimada na área alagada $($ litros de leite $)=61.981 .000^{*}$ * $(20,89 / 4.094,22)=316.246$ onde:

$20,89 \mathrm{~km}^{2}$ = área alagada do município de Uberlândia (Tabela 7)

$4.094,22 \mathrm{~km}^{2}$ = área não alagada do município de Uberlândia (Tabela 7)

Como o leite é um produto de origem pecuária, multiplicando-se a quantidade obtida por 0,0668 (Tabela 8), obtém-se 21.125,2 litros, sendo este valor relativo ao ano de 2001.
Sendo o litro de leite comercia-

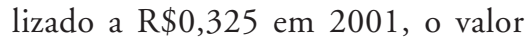
estimado associado a esta produção neste município é de $\mathrm{R} \$ 6.865,71$. Assim procedendo, produto a produto, e somando-se os valores obtidos, encontra--se um valor final para cada município, e consequentemente, para cada usina hidrelétrica.

\section{Índice de Preços por Atacado - IPA}

Alguns dos produtos presentes no banco de dados do IBGE não estavam referenciados a 2001, e sim a 1996. Para que todos os valores tivessem uma referência única, optou-se por utilizar o IPA para a padronização dos preços.

O IPA é um indicador estruturado para medir o ritmo de evolução dos preços em nível atacadista, nas transaçôes inter-empresariais. O índice considera o preço por atacado como o imediatamente anterior ao das etapas de transformação ou uso final. Essa definição permite incluir preços em diversos estágios do processo produtivo, pois abrange a utilização tanto final como intermediária dos bens (caso das matérias-primas, produtos semi elaborados, peças e componentes). É apresentado segundo dois conceitos: o da oferta global e o da disponibilidade interna. $\mathrm{O}$ conceito de oferta global abrange preços referentes a todas as transaçōes em nível de atacado efetuadas no país, inclusive preços de bens destinados à exportação. A disponibilidade interna mede a evolução dos preços das transaçóes no atacado que influenciam diretamente o poder de compra das unidades econômicas situadas dentro do país. A distinção conceitual da oferta global deve-se, ainda, ao fato de que a discriminação dos índices setoriais obedece ao critério da origem do produto, enquanto a disponibilidade interna considera o 
Tabela 8- Configuração da área alagada da UHE Miranda

\begin{tabular}{cc}
\hline Tipo de ocupação & $\%$ \\
\hline Cerradão & 15,11 \\
Cerrado & 12,51 \\
Campo Sujo/Pasto Sujo & 38,00 \\
Pasto Limpo & 6,68 \\
Cultura Anual & 3,20 \\
Rios e Afluentes & 24,50 \\
Total & 100,00
\end{tabular}

Fonte: Rosa et al, 1998

critério do destino da produção ou seu grau de elaboração.

O IPA tem periodicidade mensal e é apurado com base em pesquisa sistemática de preços realizada nas principais regiōes de produção do país, entre os dias $1^{\circ}$ e 30 do mês de referência. Além de sua composição geral, constituída por todos os elementos da amostra, o IPA desdobra-se em dois conjuntos de índices: um, com 17 itens, organizado segundo o destino que se atribui aos bens componentes (consumo/produção); o outro, com 66 itens, organizado segundo a origem de produção destes mesmos bens (agrícola/industrial). Com essa sistemática de agregação, o IPA está hierarquizado do seguinte modo: um índice geral e mais oitenta e três outros índices, que são seus subprodutos, entre os quais encontram-se produtos agrícolas, legumes, frutas, cereais, grãos, fibras vegetais, oleaginosas, raízes, tubérculos, animais, lavouras, carnes, pescados, leites e derivados (BCB, 2003).

A pesquisa de preços desenvolvese nas principais regiôes produtoras do país, especificamente nos seguintes estados: Bahia, Ceará, Espírito Santo, Goiás, Maranhão, Mato Grosso, Minas Gerais, Pará, Paraíba, Paraná, Pernambuco, Piauí, Rio de Janeiro, Rio Grande do Norte, Rio Grande do Sul, Santa Catarina e São Paulo. Os índices utilizados para a padronização dos valores estão presentes na home page da Fundação Getúlio Vargas (FGV, 2003).

Como exemplo da aplicação do IPA, consideremos mais uma vez o município de Uberlândia. Segundo os dados do IBGE, o valor total da produção de alface neste município em 1996 foi de R\$223.219,08. Utilizando-se a mesma sistemática de cálculo apresentada no sub item anterior, verifica-se que o valor estimado em reais da produção de alface na área alagada pela UHE Miranda é de R\$36,45.

De acordo com a atualização monetária de valores efetuada no site da FGV, o valor do IPA-DI para o período em estudo é de 1,7532. Desta forma, pode-se obter o valor estimado da produção para o ano de 2001, de acordo com a Equação 3:

Valor estimado de produção de alface em 2001 na área alagada pela UHE Miranda no município de Uberlândia com base no IPA-DI (em reais) $=36,45^{*}$

$* 1,7532=63,91$

onde:

$36,45=$ valor estimado em reais $\mathrm{da}$ produção de alface na área alagada do município de Uberlândia pela UHE Miranda, ano base 1996

1,75 = valor do IPA-DI período 1997-2001

\section{RESULTADOS}

Um dos poucos estudos existentes referente a questão das externalidades agropecuárias foi realizado para a Usina Hidrelétrica (UHE) de Serra da Mesa, situada no Estado de Goiás, cujas obras de construção foram iniciadas no ano de 1986. Oito municípios tiveram suas áreas atingidas pelo reservatório: Barro Alto, Campinaçu, Campinorte, Colinas do Sul, Minaçu, Niquelândia, São Luiz do Norte e Uruaçu. Segundo dados de FURNAS, a área total alagada destes municípios é de $1.784,50 \mathrm{~km}^{2}$. Deste total, $161,304 \mathrm{~km}^{2}$ eram utilizados para a pecuária, e $23,426 \mathrm{~km}^{2}$ para a agricultura.

Os principais produtos agrícolas cultivados antes do alagamento eram o milho, arroz, feijão, mandioca, cana de açúcar, soja, café, banana, abacaxi, e uma hortifruticultura de subsistência. A pecuária era voltada principalmente para o corte, apesar da existência de atividade leiteira, e utilizava pastagens naturais, a ensilagem (processo de cortar a forragem, colocá-la no silo, compactá-la e protegê-la com a vedação do silo para que haja a fermentação) e a inseminação. $\mathrm{O}$ uso agropecuário do solo em 2001 era basicamente o mesmo da época do alagamento. A produção agropecuária anual perdida pela inundação da área, em valores de 2001, foi estimada em R\$ 28.701.114,70 (Reis, 2001).

A Tabela 9 contêm os resultados das externalidades agropecuárias, obtidos de acordo com a metodologia adotada, e tendo 2001 por ano base, para todas as sete usinas hidrelétricas em estudo. Verifica-se que a UHE Nova Ponte é aquela que apresenta o maior valor de externalidade agropecuária, seguida da UHE Três Marias, ao passo que as usinas de Itutinga e Salto Grande, que entre as hidrelétricas em estudo são as que têm a menor área alagada são também as que possuem o menor valor associado a esta perda.

Efetuando-se o somatório dos valores das sete usinas hidrelétricas estudadas, obtém-se a quantia de R\$1.291.890,00, sendo este número o total das externalidades agropecuárias para o ano de 2001.

\section{Avaliação da variabilidade da área plantada}

Com base nos dados do IBGE, realizou-se uma avaliação das áreas plantadas em alguns municípios que tem suas terras parcialmente alagadas por reservatórios de usinas hidrelétricas. Tomando como exemplo a UHE Miranda, verifica-se que em 1996, ano de início das obras, ocorre uma redução na quantidade de hectares utilizados para cultivo de produtos agrícolas, conforme apresentado nas Figuras $1 \mathrm{e}$ 2 , que apresentam a alteração temporal da área plantada nos municípios de Uberaba e Uberlândia.

É possível que esta diminuição seja fruto de situações como aquela ocorrida na região alagada pela usina de Irapé, situada no Vale do Jequitinhonha, na região Nordeste de Minas Gerais. Esta obra trouxe grande prejuízo a comunidade local, visto que duas safras agrícolas foram perdidas. Os lavradores não puderam plantar na região que seria alagada, e o processo de reassentamento não foi concluído no prazo previsto devido a problemas 
relativos a documentação de posse de terra e a sua aquisição, de acordo com o termo de ajuste intermediado pelo STF - Superior Tribunal Federal (CREA-MG, 2005).

Observando-se as Figuras 1 e 2 , verifica-se que no ano seguinte ao início das obras ocorre um aumento na quantidade de hectares plantados. É possível que este incremento seja devido as atividades agrárias promovidas pelas famílias reassentadas.

Algumas hipóteses podem explicar o crescimento da área plantada nos anos subsequentes a construção do lago. Este aumento pode não ter sido um fenômeno local, e sim ocasionado por novas políticas agrícolas implementadas pelo governo federal, como o plano safra 1997/1998 que incluía maior disponibilidade de créditos aos produtores, novos preços mínimos, o seguro agrícola PROAGRO (IPEA_a, 1997), além da quantidade recorde de fertilizantes entregue aos agricultores neste período, $13 \%$ maior que a registrada no ano anterior (IPEA_b, 1997).

\section{Valoração das externalidades em função do custo de geração das usinas}

Para se analisar a significância dos números obtidos, resolveu-se comparar o valor da externalidade com o custo de geração dos aproveitamentos em estudo. A geração de energia das sete usinas hidrelétricas e sua tarifa associada, de acordo com dados obtidos junto à Gerência de Planejamento de Mercado da CEMIG, é apresentada na Tabela 10. Desta forma, tem-se como mensurar a ordem de grandeza das externalidades associadas à perda agropecuária em função do custo de geração das usinas hidrelétricas.

Com base nos resultados obtidos verifica-se que, para todas as sete usinas hidrelétricas em estudo, o valor da externalidade agropecuária possui pouca significância quando comparado ao custo de geração de energia elétrica.

\section{Valoração das externalidades em função do PIB Municipal}

Através de consulta ao Site do IBGE obteve-se o PIB, de cada um dos 39 municípios em estudo, referente ao ano de 2001. O valor do PIB foi com-

Tabela 9 - Resultados das externalidades agropecuárias

\begin{tabular}{cc}
\hline UHE & $\begin{array}{c}\text { Valor da externalidade agropecuária } \\
\text { (mil Reais) }\end{array}$ \\
\hline Salto Grande & 2,039 \\
Itutinga & 2,063 \\
Camargos & 27,449 \\
Miranda & 88,133 \\
Três Marias & 411,610 \\
Nova Ponte & 580,66 \\
Emborcação & 179,96 \\
\hline
\end{tabular}

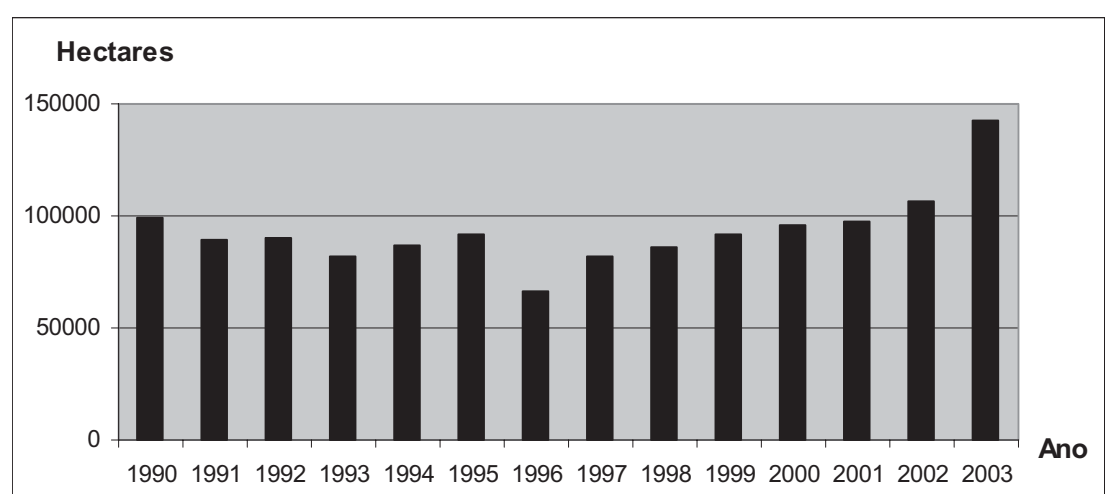

Figura I - Alteração temporal da área plantada - lavoura temporária, município de Uberaba

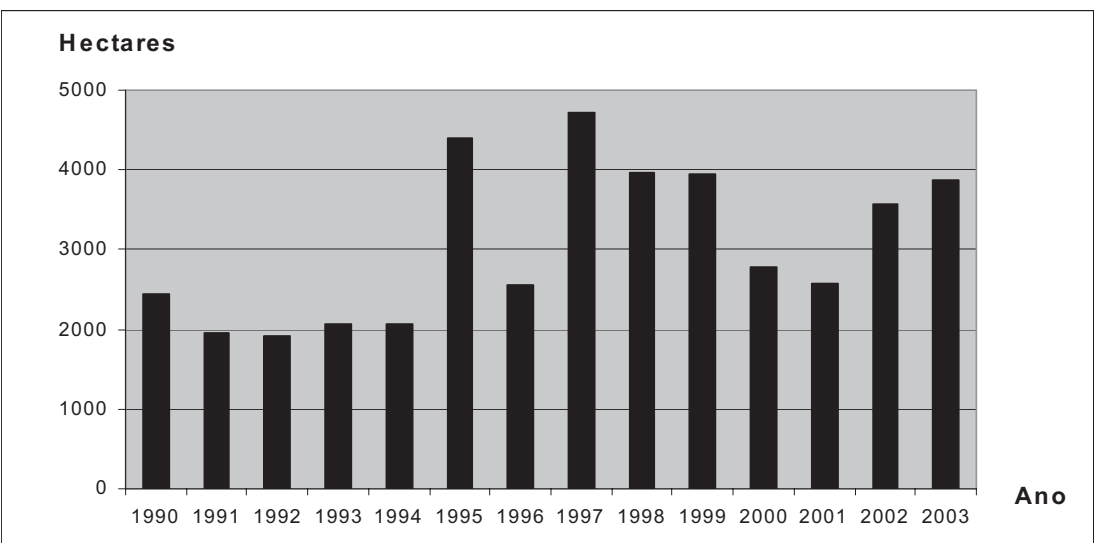

Figura 2 - Alteração temporal da área plantada - lavoura permanente, município de Uberlândia

parado ao valor da externalidade, a nível municipal. Verificou-se que quando a fração da área municipal alagada é pequena, o valor das externalidades agropecuárias é pouco significativo. Entretanto, nos municípios nos onde o percentual da área inundada pelos reservatórios é relevante, observa-se que a relação entre o PIB municipal e as externalidades agropecuárias apresenta valores mais significativos. Isto demonstra que quanto maior o valor da área municipal inundada, maior a significância da externalidade agropecuária em função do PIB daquela localidade.

Dos oito municípios com a relação mais próxima (menor) entre o PIB e as externalidades agropecuárias, sete deles possuem também o maior percentual de suas terras inundadas, conforme pode ser verificado na Tabela 11 . A exceção é o município de Perdizes, que apesar de ter 4,55\% de sua área alagada pela represa de Nova Ponte, possui uma relação PIB/externalidade mais 
relevante devido ao valor de sua perda agropecuária, pois os produtos oriundos da lavoura temporária e da silvicultura geram expressiva receita ao município, conforme os dados do IBGE, quando comparados com outros municípios alagados em estudo.

O valor da externalidade agropecuária, no caso de municípios que tenham um PIB mais elevado, como Uberaba (R\$2.734.967) e Uberlândia ( $\mathrm{R} \$ 5.560 .741)$, é pouco significativo.

Entre todos os municípios analisados, verificou-se que aquele que possui o valor da externalidade agropecuária mais próximo ao valor do PIB foi Grupiara, parcialmente inundado pelo lago de Emborcação. Deve-se considerar que esta localidade tem mais de $40 \%$ de sua área alagada, por isso o valor do passivo é maior. Ressalta-se aqui que, entre os municípios em estudo, Grupiara é justamente o que tem o maior percentual de suas terras alagadas. Em segundo lugar em percentual municipal inundado aparece o município de Morada Nova de Minas, que tem 23\% de seu área alagada pela represa de Três Marias. Este município também apresenta a segunda relação mais próxima entre o valor do PIB e da externalidade agropecuária, entre os 39 municípios em estudo.

\section{CONCLUSÕES}

São vários os problemas existentes para estimar o valor das externalidades, entre os quais cita-se a dependência para com as tecnologias utilizadas e da localização das usinas geradoras, as incertezas nas causas e natureza dos impactos para a saúde e o ambiente, os reduzidos estudos de avaliação econômica e as questóes metodológicas envolvendo a utilização dos resultados econômicos e ambientais. Incluem-se ainda a carência de metodologias para avaliação adequada de impactos ambientais como mapas temáticos, listagens de verificação e matrizes de interação, e a deficiência de mecanismos para articular a atuação dos empreendedores com as instituições responsáveis pela política econômica e social das regiôes atingidas e para garantir a participação dos grupos afetados na tomada de decisão desde a fase inicial do ciclo de planejamento da geração hidrelétrica, que compreende a estimativa do potencial, o inventário, $\mathrm{o}$ estudo de viabilidade, o projeto básico e o projeto executivo.

A ausência de alguns dados relevantes, tais como a fração da área alagada destinada a produção agropecuária para outras usinas que não a de Miranda, dificultou sobremaneira que resultados mais precisos fossem encontrados. De qualquer forma, devido a inexistência de trabalhos similares e, consequentemente, de outras metodologias que pudessem ser empregadas para se estimar o valor da externalidade, estabeleceu-se um ponto de partida válido para que resultados numéricos pudessem efetivamente ser encontrados. Considera-se que se for possível obter um banco de dados completo a aplicação desta metodologia, a mesma pode propiciar uma boa estimativa da externalidade agropecuária associadas

Tabela 10 - Valoração das externalidades em função do custo de geração

\begin{tabular}{|c|c|c|c|c|c|}
\hline $\begin{array}{l}\text { Nome do } \\
\text { aproveitamento }\end{array}$ & $\begin{array}{c}\text { Tarifa } \\
\mathrm{R} \$ / \mathrm{MWh}\end{array}$ & $\begin{array}{c}\text { Custo da } \\
\text { externalidade } \mathrm{R} \$\end{array}$ & $\begin{array}{l}\text { Geraçãoo } \\
\text { MWh }\end{array}$ & $\begin{array}{c}\text { Custo da } \\
\text { externalidade }-\mathrm{R} \$ / \mathrm{MWh}\end{array}$ & $\begin{array}{l}\text { Relação custo da externalidade } \\
\text { por custo de geração }\end{array}$ \\
\hline UHE Camargos & 41,00 & $27.449,00$ & 108.034 & 0,25 & $0,62 \%$ \\
\hline UHE Três Marias & 41,00 & $411.610,00$ & 1.140 .336 & 0,36 & $0,88 \%$ \\
\hline UHE Salto Grande & 41,00 & $2.039,00$ & 375.322 & 0,01 & $0,01 \%$ \\
\hline UHE Emborcação & 41,00 & $179.968,00$ & 1.980 .328 & 0,09 & $0,22 \%$ \\
\hline UHE Itutinga & 41,00 & $2.063,00$ & 157.622 & 0,01 & $0,03 \%$ \\
\hline UHE Miranda & 41,00 & $88.133,00$ & 1.090 .056 & 0,08 & $0,19 \%$ \\
\hline UHE Nova Ponte & 41,00 & $580.663,00$ & 1.143 .154 & 0,50 & $1,23 \%$ \\
\hline
\end{tabular}

Fonte: CEMIG 2004/ANEEL 2004/Elaboração própria

Tabela II - Valoração das externalidades em função do PIB municipal

\begin{tabular}{cccccc}
\hline Município & UHE & $\begin{array}{c}\text { \% municipal } \\
\text { alagado }\end{array}$ & $\begin{array}{c}\text { PIB 2001 - valor } \\
\text { em mil reais }\end{array}$ & $\begin{array}{c}\text { Externalidade } \\
\text { agropecuária - valor } \\
\text { em mil reais }\end{array}$ & $\begin{array}{c}\text { Relação } \\
\text { PIB/Externalidade } \\
\text { agropecuária }\end{array}$ \\
\hline Grupiara & Emborcação & 40,21 & 5.377 & 35,26 & 152,52 \\
Douradoquara & Emborcação & 14,90 & 7.114 & 19,49 & 364,95 \\
Paineiras & Três Marias & 8,57 & 17.443 & 36,35 & 479,87 \\
Pedrinópolis & Nova Ponte & 15,84 & 22.290 & 68,00 & 327,77 \\
Morada Nova de Minas & Três Marias & 23,79 & 29.682 & 107,67 & 275,67 \\
Iraí de Minas & Nova Ponte & 16,14 & 30.526 & 94,75 & 322,19 \\
Felixlândia & Três Marias & 10,17 & 41.634 & 70,20 & 593,07 \\
Perdizes & Nova Ponte & 4,55 & 98.465 & 165,54 & 594,81 \\
\hline
\end{tabular}

Fonte: CEMIG 2004/ANEEL 2004/Elaboração própria 
a perda de produção devido ao alagamento de terras cultivadas e de áreas utilizadas para atividade pecuária.

A inexistência até o presente momento de outras metodologias que quantifiquem os impactos associados a este tipo de perda justifica estudos nesta linha de pesquisa. Os valores encontrados são pequenos quando comparados à tarifa de energia elétrica; desta forma, de acordo com a metodologia utilizada e no caso destas hidrelétricas, pode-se concluir que o custo das externalidades agropecuárias é pouco significativo. Todavia, quando efetuada a avaliação das externalidades agropecuárias em função do PIB municipal verifica-se que, quanto maior é o valor da área municipal inundada pelo lago, mais significativa é o valor da mesma.

Deve-se também considerar que os reservatórios propiciam em alguns casos o aumento do turismo na região alagada, devido ao seu potencial relacionado à prática de esportes aquáticos e atividades recreacionais. Como exemplo o lago de Furnas, no Estado de Minas Gerais, constitui-se em uma grande atração turística, o que contribuiu para o crescimento da rede hoteleira devido às várias opções de lazer associadas ao local, inclusive a prática de esportes radicais, entre outros. Desta forma, torna-se complexa a avaliação comparativa dos benefícios e dos passivos gerados quando da implantação de um reservatório.

\section{AGRADECIMENTOS}

Os autores expressam seus agradecimentos a ANEEL, através do Sr. Cristiano Abijaode Amaral, e a CEMIG, através do Sr. Júlio César Ezequiel da Costa e do Sr. José Geraldo Montuori.

\section{REFERÊNCIAS}

BCB - BANCO CENTRAL DO BRASIL. www.bcb.gov.br. Acessado em 04/12/2003.

CAUFIELD, C. Masters of Illusion: The World Bank and the Poverty of Nations. Henry Holt and Company, New York, 1996.

CREA-MG - Jornal Vértice., pgs. 4 e 5 . Janeiro de 2005 .

EDMONDS, R. L. The Sanxia (Three Gorges) Project: the Environmental Argument Surrounding China's Super Dam. Global Ecology and Biogeography Letters 2: 105-125. 1992.

FERREIRA, V. V. M. Avaliação de Externalidades do Setor Hidrelétrico no Estado de Minas Gerais. Tese de Doutorado. SMARH/UFMG. 198 pag. 2004.

FGV - FUNDAÇÃO GETÚLIO VARGAS. http://fgvdados.fgv.br/dsp frs pai ferramentas. asp Acessado em 01/12/2003.

IBGE - INSTITUTO BRASILEIRO DE GEOGRAFIA E ESTATÍSTICA - www.ibge.gov. br. Acessado em 25/07/2003.

IPEA a - INSTITUTO DE PESQUISA ECONÔMICA APLICADA. Boletim Conjuntural numero 38, julho de 1997. www.ipea.gov.br/pub/bccj/bc038g.html. Acessado em 28/09/1997.

IPEA_b - INSTITUTO DE PESQUISA ECONÔMICA APLICADA. Boletim Conjuntural número 37, abril de 1997. www.ipea. gov.br/pub/bccj/bc037g.html. Acessado em 28/09/1997.

JACOMINO, V. M. F.et al. Estimativa das Externalidades Associadas às Emissōes Atmosféricas do Ciclo de Produção de Energia Elétrica. V ENAN - Encontro Nacional de Aplicaçōes Nucleares. Rio de Janeiro. CD Rom. 2000.

MCCULLY, P. Silenced Rivers: The Ecology and Politics of Large Dams. London, Zed Books, 1996.

MORRISH, M. The Living Geography of China. Geography 82:3-16. 1997.

MURPHY, B. The Politics and Economics of Large-Scale Hydropower Dams. California State University Fullerton Graduate Seminar on Cultural Ecology. USA, 2001.

REIS, M. M., Custos Ambientais Associados a Geração Elétrica: Hidrelétricas x Termelétricas a Gás Natural. Dissertação. Rio de Janeiro: UFRJ/COPPE, 200pag. 2001.

ROSA, L. P. et al. Emissóes de Gases de Efeito Estufa Derivados de Reservatórios Hidrelétricos. COPPE/UFRJ e COPPETEC, 1998. Acessado em 04/02/2003. http://www.mct.gov.br/clima/ comunic old/methid.htm

SCUDER, T. Development-induced Relocation and Refugee Studies: 37 Years of Change and Continuity among Zambia's Gwembe Tonga. Journal of Refugee Studies 6:123-152. 1993.

WEIST, K. M. Development Refugees: Africans, Indians and Big Dams. Journal of Refugee Studies 8: 163-184. 1995

WORLD COMMISSION ON DAMS. Dams and development: a new framework for decision making. Earthscan Ltd., Londres, novembro de 2001.

Endereço para correspondência:

Vinícius Verna M. Ferreira

CDTN - Centro de

Desenvolvimento da Tecnologia

Nuclear

Universidade Federal de Minas

Gerais - UFMG

Rua Professor Mário Werneck, $s / n^{\circ}$

Caixa Postal 94 I Campus

30I 23-970 Belo Horizonte - MG

- Brasil

Tel: (3I) 3069-3244

Fax: (3I) 3069-3I 74

E-mail: vvmf@cdtn.br 